\title{
Surgical Pearl: Disposable Hypodermic Needle Punch
}

\author{
Muhammed Mukhtar (iD) 1," \\ ${ }^{1}$ Mukhtar Skin Centre, Kmch Road, Katihar-854105, India \\ "Corresponding author: Mukhtar Skin centre, KMCH Road, Katihar-854105, India. Email: drmmukhtar20@gmail.com \\ Received 2020 June 14; Accepted 2020 August 13.
}

Keywords: Hypodermic Needle, Gauge, Needle Punch, Dental Burr, Mini File, Dermabrader, Mini Punch Graft, Vitiligo

\section{Dear editor,}

Vitiligo remains a major challenge in dermatology, and many patients experience an incomplete therapeutic response to the conventional medical therapy (1). As a result, several surgical interventions are developed for vitiligo, such as ultra-thin thiersch grafting, epidermal grafting, and melanocytes transplantation, by both cultured and noncultured techniques (2). However, some small residual lesions remain persistent over the treated sites even after proper medical and surgical treatments (3), which indicates that a large size graft is not necessary. In order to achieve better cosmetic results, a mini punch graft should be used $(4,5)$. However, mini punches are not readily available. Meanwhile, the profit margin of producing punch is small; hence, manufacturers are not incentivized to produce such devices, which resulted in the low supply of punches to the market. In response to this situation, disposable punches can be produced in clinics using a hypodermic needle. Here I suggest a simplified method for procuring the punch in clinics as an economical alternative to the disposable mini needle punch in such situations.

For preparing mini punch, the following items are needed: hypodermic needle, needle holder, watchmaker conical mini file, dental bur, and manual dermabrader. The inner and outer diameters of $14,15,16,18$ gauge hypodermic needles are 1.6/2.1, 1.4/1.8, 1.2/1.6, and 0.8/1.2 mm, respectively. These needles are readily available. Here I selected 16 and 18G needles (Figure 1A). The distal part of the needle was broken gently using a needle holder. Afterward, it was rubbed gently for few strokes on a flat surface of a mini file or a manual dermabrader to smoothen the broken punching end of the needle. Then, a dental burr and a mini conical file were inserted into the needle from its broken part to make the lumen round as it gets distorted little bit after breaking the needle shaft. In the following, the needle was rotated over the conical surface of the file to sharpen the punching end of the needle (Figure 1B-D). After this, the outer surface of the needle was also rubbed from all-around gently on the file. On completion of the sharpening of the needle, the diameters of punches were found uniformly round on a measuring scale(Figure 1E). Its diameter was found $1.4 \mathrm{~mm}$ and $1.0 \mathrm{~mm}$ of $16 \mathrm{G}$ and $18 \mathrm{G}$ needles, respectively. This needle punch can be handled with a syringe, and its punching end can be guarded with the cap of the needle. Thus, a hypodermic needle punch can be prepared in case of emergency, and it is a good economical alternative to the disposable punch, after chemical disinfection, for mini punch grafting in vitiligo (Figure 1F).

\section{Footnotes}

Authors' Contribution: Being the only author, all contributions are made by the author.

Conflict of Interests: The author declares no conflict of interest.

Funding/Support: There was no funding/support.

\section{References}

1. Rodrigues M, Ezzedine K, Hamzavi I, Pandya AG, Harris JE, Vitiligo Working G. Current and emerging treatments for vitiligo. J Am Acad Dermatol. 2017;77(1):17-29. doi: 10.1016/j.jaad.2016.11.010. [PubMed: 28619557].

2. Bae JM, Ju HJ, Lee RW, Lee HN, Kim NB, Kim YH, et al. Micropunch grafting as an adjuvant for noncultured melanocytes-keratinocyte transplantation for refractory vitiligo.J Am Acad Dermatol.2020;82(6):154850. doi: 10.1016/j.jaad.2020.03.003. [PubMed: 32160974].

3. Silpa-Archa N, Griffith JL, Huggins RH, Henderson MD, Kerr HA, Jacobsen $\mathrm{G}$, et al. Long-term follow-up of patients undergoing autologous noncultured melanocyte-keratinocyte transplantation for vitiligo and other leukodermas. J Am Acad Dermatol. 2017;77(2):318-27. doi: 10.1016/j.jaad.2017.01.056. [PubMed: 28502377].

4. Hurkudli DS, Sarvajnamurthy S, Suryanarayan S, Chugh VS. Novel uses of skin biopsy punches in dermatosurgery. Indian J Dermatol. 2015;60(2):170-5. doi: 10.4103/0019-5154.152519. [PubMed: 25814706]. [PubMed Central: PMC4372910].

5. Kato H, Furuhashi T, Ito E, Kaneko N, Nakamura M, Watanabe S, et al. Efficacy of 1-mm minigrafts in treating vitiligo depends on patient age, disease site and vitiligo subtype. J Dermatol. 2011;38(12):1140-5. doi: 10.1111/j.1346-8138.2010.01184.x. [PubMed: 21951328]. 

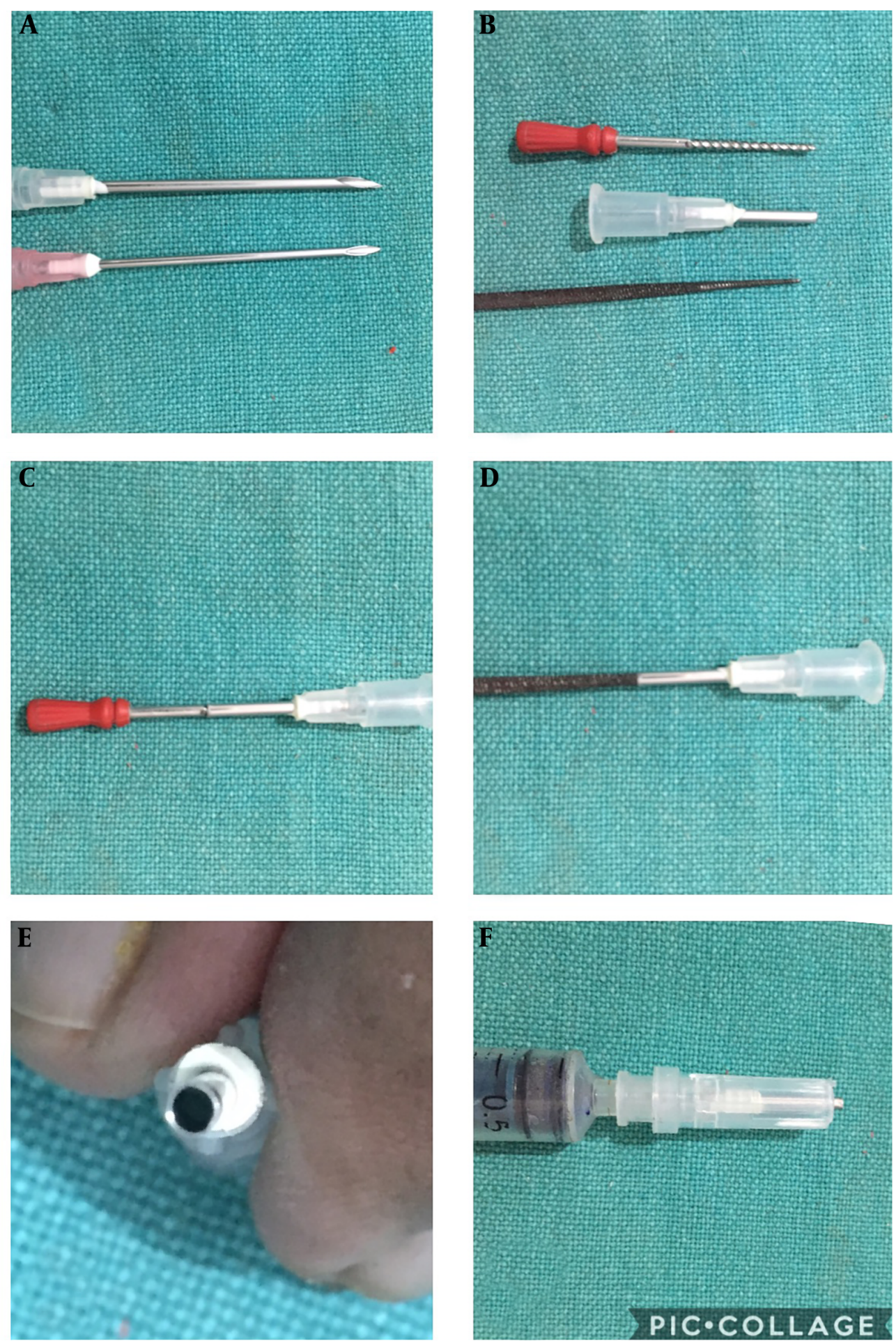

Figure 1. A, The 16 and $18 \mathrm{G}$ needle for procuring needle punch; B-D, The needle is broken and sharpen with dental burr and conical mini file; E, The needle is ready for punching the lesion; F, The hypodermic needle punch guarded with its cap 